Running Head: SOCIOCULTURAL PRESSURE AND APPEARANCE-RS

\title{
“Pretty Pressure” from Peers, Parents, and the Media: A Longitudinal Study of Appearance-based Rejection Sensitivity
}

\author{
Haley J. Webb \\ Melanie J. Zimmer-Gembeck \\ Allison M. Waters \\ Lara J. Farrell \\ Drew Nesdale
}

Griffith University, School of Applied Psychology and Menzies Health Institute of Queensland and

Geraldine Downey

Columbia University, Department of Psychology

Corresponding Author:

Dr Haley Webb

School of Applied Psychology and Menzies Health Institute

Griffith University,

Gold Coast Australia. 4222

Email: haley.webb@griffithuni.edu.au

Phone: +61 (0)7 56788688 


\begin{abstract}
Drawing from the tripartite sociocultural model of body image, we examined whether direct messages and modeling from peers, parents, and media were concurrently and prospectively associated with appearance-based rejection sensitivity (appearance-RS) in young adolescents ( $M_{\text {age }}$ $=12.0$ years). Appearance-RS was higher among those who concurrently reported more appearance-related teasing and pressure by peers, more parent teasing, and greater acceptance of media appearance ideals. In prospective analyses, greater increases in appearance-RS over one year were found for adolescents who perceived higher levels of parental appearance-related teasing and negative attitudes about their own appearance. Moderation analyses indicated the positive prospective association between parental negative appearance attitudes and appearanceRS was found in younger but not older participants. Gender did not moderate associations.
\end{abstract}




\section{“Pretty Pressure” from Peers, Parents, and the Media: A Longitudinal Study of Appearance-based Rejection Sensitivity}

More than ever before people who meet stringent standards and ideals of beauty and fitness are highly valued, becoming famous or followed on Twitter or Instagram for nothing more than their looks, their body shape and size, or their fitness regime. Therefore, it is not so surprising that body image and appearance have been identified as one of the top three concerns of adolescents (Fildes, Robbins, Cave, Perrens, \& Wearring, 2014; Perrens et al., 2013). In some of these same studies, young people identified their friendships and family relationships as most highly valued, and reported that they also highly value sustained connection with friends, peers, and a worldwide community through a multitude of social media platforms (Allen, Ryan, Gray, McInerney, \& Waters, 2014; Madden et al., 2013).

Drawing together concerns about physical appearance and attractiveness with the pervasive human psychological need for connection and belonging (Baumeister \& Leary, 1995), appearance-based rejection sensitivity (appearance-RS) has been described as a bias that involves anxious concerns about, heightened expectations of, and overreactions to perceived social rejection, and attributions for this rejection to aspects of physical appearance (Park, 2007; Park, DiRaddo, \& Calogero, 2009). Appearance-RS differs from body dissatisfaction, as appearance-RS involves negative thoughts and feelings about appearance more broadly, and explicitly relates these negative thoughts to fears about being accepted or rejected by others. On the other hand, body dissatisfaction focuses on negative thoughts and feelings about the body (Grogan, 2008) and tends to covary with body size (Presnell, Bearman, \& Stice, 2003), while appearance-RS does not (Webb \& Zimmer-Gembeck, 2015; Webb et al., 2014).

Adolescents and adults who are higher in appearance-RS report poorer self-esteem, more restrictive eating behavior, elevated risk for body dysmorphic disorder and greater acceptance of 
cosmetic surgery than their peers with lower appearance-RS (Park, 2007; Park, Calogero, Young, \& DiRaddo, 2010; Webb \& Zimmer-Gembeck, 2015). Moreover, appearance-RS has important implications for social relationships. Specifically, individuals who are high in appearance-RS report heightened fears of negative evaluation and a tendency to withdraw socially (Bowker, Thomas, Spencer, \& Park, 2013; Park \& Pinkus, 2009). They have also been observed to respond to even ambiguous signs of rejection in self-defeating ways that act to perpetuate the social isolation and rejection that they expect and fear (Park \& Pinkus, 2009). Given that appearance-RS involves social affective processing biases that result in interaction patterns that inadvertently perpetuate social dysfunction, it poses a risk for an escalating cycle of pathology and dysfunction.

\section{Why Focus on Young Adolescents?}

In light of the significant personal and interpersonal maladaptation associated with appearance-RS, researchers have turned to explaining why it occurs among some people more than others. Much of the research on appearance-RS has relied on university students or adults as participants. Yet, the age period from 10 to 14 years (often referred to as early adolescence) is a particularly important time to examine body image concerns, including appearance-RS. These years encompass a period of time during which pubertal development begins (Paikoff \& BrooksGunn, 1991), and concerns about physical appearance reach their peak and generally stay stable for some time thereafter (Rumsey \& Harcourt, 2005; Wertheim, Paxton, \& Blaney, 2004). These increases in appearance concerns can come about because of physical changes (Stice, 2003), but they may also be a result of the development of identity and self-competence (Harter, 1999), and the fact that attractiveness often brings higher social status in adolescents’ peer groups (Hyde, Cillessen, \& Borch, 2011). In addition, exposure to various media is escalating among children and adolescents, with the use of social media in particular comprising the most common daily pursuit for young people (O’Keefe, Clarke-Pearson, \& Council of Communications and Media, 
2011). For these reasons, we focus on these early years of adolescence.

\section{Tripartite Sociocultural Influence Model}

Drawing from the Tripartite Social Influences Model (Thompson, Heinberg, Altabe, \& Tantleff-Dunn, 1999) and the Sociocultural Model of Disordered Eating (Stice, 1994), we theorized that the substantial involvement that adolescents have with peers, family, and the media, and the salience of these social environments for adolescents, would mean that all three social domains are relevant to identifying those adolescents who showed greater increases in appearanceRS relative to others (Park et al., 2009; Webb, Zimmer-Gembeck, \& Donovan, 2014). In particular, peers and the media, and even the family (particularly parents), can provide powerful messages about unrealistic and potentially unattainable appearance ideals, as well as the seemingly limitless benefits of achieving those ideals. These sociocultural forces can serve to perpetuate appearance concerns and drive efforts to enhance attractiveness (Menzel et al., 2011).

In cross-sectional studies, peers' attitudes and behaviors have been found to have moderate to strong influences on adolescent behavior, including on their appearance concerns (Bowker et al., 2013; Webb \& Zimmer-Gembeck, 2015). During early adolescence time spent with close friends and other peers in and out of school increases, and this continues right through all of adolescence (Zimmer-Gembeck, Siebenbruner, \& Collins, 2001; Furman \& Buhrmester, 1992; Furman, Brown, \& Feiring, 1999; Zimmer-Gembeck, 1999, 2002). This increasing time with peers is linked with a rise in concerns about peer acceptance and approval, as well as greater intimacy with peers (Bukowski, Newcomb, \& Hartup, 1998; Zimmer-Gembeck, 1999, 2002). In contrast to peers, parents may be important in shaping appearance-related attitudes and concerns during childhood, but in studies of older adolescents the influence of parents has been found to be weaker, especially in comparison to the influence of friends and other peers (Paxton, Eisenberg, \& Neumark-Sztainer, 2006; Rodgers, Chabrol, \& Paxton, 2011; Shroff \& Thompson, 2006). It 
remains unclear whether parents influence appearance-RS during the transitional age period of early adolescence. Moreover, the role of the media in shaping adolescents' attitudes and beliefs appears to be increasingly relevant in an era of instant access to international television series and movies, broad participation in social media, and online sharing of information about the ideal body and appearance (Tiggemann \& Slater, 2013, 2014).

Peers, parents and the media have been examined together in one previous study on appearance-RS, but this study examined a small number of sociocultural factors, and only reported concurrent associations. Specifically, Park et al. (2009) found that appearance-RS was higher in young adults (Mdn age = 19 years) who also reported greater internalization of media ideals, more perceived pressure from the media to look attractive, and elevated perceptions that one's acceptance by friends was conditional on appearance. Parents’ valuing of appearance and parental appearance-conditional acceptance were not associated with appearance-RS in young adults. Overall, these findings are consistent with the idea that during adolescence and into adulthood, parental influence may not be significant once the influence of peer relationships and the media are considered. However, given that so little research has been conducted with early adolescents, these findings leave it unclear whether peers, parents and the media each play an important role in appearance-RS in this transitional age period.

Parental influence. Parents represent the most immediate and significant source of influence during childhood, and researchers have advocated for the continued centrality of parentchild relationships in research beyond childhood into the earliest years of adolescence (Collins \& Laursen, 2004b). RS theory (Downey, Bonica, \& Rincon, 1999) and research suggests that a general sensitivity to rejection develops from a history of real or perceived rejection experiences (Butler, Doherty, \& Potter, 2007; Downey \& Feldman, 1996; Downey, Khouri, \& Feldman, 1997). Extending this theory to appearance-RS, this suggests that adverse appearance-related 
experiences that imply or involve rejection would leave a psychological legacy in the form of heightened sensitivity to appearance-based rejection. Although no longitudinal research has examined this hypothesis, experimental research has shown that individuals with elevated appearance-RS report feeling more alone and rejected after recalling a critical comment made about their appearance (Park, Calogero, Harwin, \& DiRaddo, 2009). These findings suggest that appearance teasing from parents, as well as perceived pressures to be more attractive from family members, would be particularly influential in the development or exacerbation of appearance-RS. Parental modeling of appearance and body image concerns has also been identified as a key predictor of children's body image attitudes and eating behaviors, whereby parents' appearance-related attitudes and behavior are thought to transmit powerful messages about appearance ideals (Ricciardelli \& McCabe, 2001). However, the evidence is less consistent regarding whether the influence of parents on appearance attitudes and concerns continues into adolescence and young adulthood (e.g., Rodgers, Paxton, \& Chabrol, 2009; Shroff \& Thompson, 2006; Wood Baker et al., 2000). Notably, the existing research on appearance-RS has not found parental factors to be unique, concurrent correlates during emerging adulthood (Park et al., 2009). However, no previous study has focused on a younger age group, nor examined more than one or two parent factors.

Peer influence. The peer context is considered a particularly influential social force, to which adolescents are exposed on a daily basis, and in which adolescents are highly invested (Collins \& Laursen, 2004a). Peer appearance teasing and pressure from peers to be attractive are the most widely studied peer influences in relation to adolescent appearance concerns (Webb \& Zimmer-Gembeck, 2014), whereby they convey and reinforce appearance ideals, and provide social pressure to conform. These peer influences are consistently associated with elevated body image concerns (Webb \& Zimmer-Gembeck, 2014), and have also emerged as potentially 
important channels of influence in relation to appearance-RS. Specifically, in one study that considered a range of peer factors (e.g., peer appearance conversations, teasing, and values), pressure from peers to be attractive showed the strongest bivariate positive association with concurrent appearance-RS in early adolescents (Webb et al., 2014). Moreover, peer appearance teasing has been found to show a unique positive association with adolescent appearance-RS in a model that included a range of peer factors (Webb et al., 2014).

In addition, appearance-focused conversations with friends are thought to contribute to a greater focus on, and value of, appearance and attractiveness within the friendship context, and have been argued to function to reinforce appearance ideals and self-evaluation on the basis of perceived attractiveness (Jones, 2004; Jones, Vigfusdottir, \& Lee, 2004). Notably, more frequent appearance conversations with friends during adolescence have consistently been found to be linked both concurrently and longitudinally with elevated body image concerns (Jones, 2004; Jones et al., 2004; Webb \& Zimmer-Gembeck, 2014), and have been shown to be concurrently associated with heightened appearance-RS (Webb et al., 2014).

Media influence. Appearance-related influences from the media, such as internalization of appearance ideals and perceived pressure from the media, have consistently been linked with greater concurrent and prospective body dissatisfaction (Stice \& Whitenton, 2002; Thompson \& Stice, 2001), and have been found to be concurrently associated with young adult concerns about appearance-based rejection in the one study that has assessed this association (Park et al., 2009). Perceived pressure from the media to be attractive involves feelings of both direct and indirect appearance-related pressures (Stice \& Whitenton, 2002), whereas internalization of media portrayed appearance ideals involves personally "buying into” the largely unrealistic ideals depicted in the media, and accepting them as an appropriate appearance standard (Thompson \& Stice, 2001). Internalization of media ideals is theorized to place people at heightened risk of 
developing concerns about their own physical appearance (Thompson \& Stice, 2001, p. 181), and provides a good assessment of the interpretation of media images rather than measuring media consumption.

Age and sex effects. Body image and appearance concerns are topics traditionally examined predominantly in females (Helfert \& Warschburger, 2013). However, as measures have been modified to focus on appearance more generally or alternative aspects of appearance (i.e., muscularity) rather than the thin ideal, research is increasingly showing that males also report problematic body image attitudes and appearance concerns, albeit the focus of male concerns may differ somewhat from females (i.e., achieving lean muscularity versus reducing body weight; Bearman, Presnell, Martinez, \& Stice, 2006; McCreary \& Sasse, 2000; Riccardelli \& McCabe, 2007). In relation to appearance-RS in particular, cross-sectional research on adolescents and adults has shown that young women report higher appearance-RS than young men, but no gender differences have been reported in associations between social influence variables and adolescent appearance-RS (Park et al., 2009; Webb et al., 2014; Webb \& Zimmer-Gembeck, 2015).

Concerns about appearance are typically found to peak during adolescence (Littleton \& Ollendick, 2003), theoretically due to an interplay between social, emotional and physical development. For example, adolescents experience rapid physical changes that can cause deviations from appearance ideals, increasing self-focus, introspection and exploration (Azmitia, 2002; Stice, 2003). In longitudinal research, studies have shown that girls' body dissatisfaction tends to increase (and positive body-esteem tends to deteriorate) up until mid-adolescence (Clark \& Tiggemann, 2008; Frisen, Lunde, \& Ingeborg, 2015). In boys, the pattern is less clear, but some longitudinal research reports a decline in boys' body-esteem during early and middle adolescence (Eisenberg, Neumark-Sztainer, \& Paxton, 2006) and even up to the 20s (Frisen et al., 2015). Moreover, adolescents experience increasing intimacy with peers and autonomy from parents, and 
initiation of romantic interests and relationships (Collins \& Laursen, 2004a, 2004b). These changing relationship dynamics, in addition to increasing engagement in various media during adolescence (Rideout, Foehr, \& Roberts, 2005) suggests that the influence of peers, parents and the media may change during this time. Accordingly, a sample of early adolescents (i.e., 9 - 14 years) was the focus of the present study to capture this important developmental period.

Covariates: RS, attractiveness, and body mass index (BMI). Whereas body image concerns tend to be linked with body size and shape (Paxton et al., 2006), researchers have not considered whether appearance-RS differs according to body size in adults. Among adolescents, researchers have found no significant association between appearance-RS and BMI (Webb \& Zimmer-Gembeck, 2015; Webb et al., 2014), supporting the suggestion that appearance-RS encompasses broader conceptions of appearance than simply body size. Conceptually, however, it would seem that persons who are considered less objectively attractive may be more susceptible to appearance-RS. Moreover, appearance-RS has been found to show moderate associations with general rejection sensitivity (general-RS) in adults and adolescents (Bowker et al., 2013; Park, 2007; Park \& Pinkus, 2009). General-RS, BMI and attractiveness may be important covariates in relation to appearance-RS, and as such, will be assessed and controlled for in the present study.

\section{Summary, Study Aim and Hypotheses}

The study of RS specific to physical appearance has vital implications for sufferers' selfperceptions and distress, as well as for their social engagement and functioning. However, there remain three key gaps in the literature. First, the existing research has considered a small number of sociocultural influence factors or factors within one sociocultural domain (e.g., peer factors only). Second, much of the research on appearance-RS has focused on adults, despite evidence that appearance concerns tend to emerge and peak during adolescence (Littleton \& Ollendick, 2003). Finally, previous literature has relied on cross-sectional research designs that are unable to 
isolate direction of effects.

The present study provides an important contribution to the existing literature on appearance-RS through a comprehensive examination of the sociocultural context for an early adolescent sample using a prospective research design, thus permitting greater confidence in conclusions about temporal sociocultural risk factors for the development of appearance-RS. Specifically, the present study drew from the Tripartite Social Influences Model (Thompson et al., 1999) to comprehensively examine the sociocultural forces that covary with elevations in appearance-RS among early adolescents, and to test whether relative increases in appearance-RS over one year can be accounted for by these social forces (see Figure 1). It was hypothesized that adolescents’ appearance-RS would show greater increases over one year when they experienced more peer appearance teasing, pressure to be attractive from peers, and appearance conversations with friends, as well as more appearance teasing by parents, perceived pressure to be attractive from family members, and parents’ negative appearance attitudes. Adolescents’ appearance-RS would also show greater increases when they experienced more pressure from the media to be attractive and internalization of appearance ideals portrayed in the media. To ensure the present results are not due to general tendencies toward RS, or due to physical attributes, general-RS, researcher-measured BMI percentile and peer-reported attractiveness were assessed and controlled for in all analyses.

Moreover, the present study focused on a sample of early adolescents (i.e., 9 - 14 years of age), and an additional aim of the present study was to assess differences between younger and older participants within this transitional developmental period in the relative importance of parent, peer and media factors. Specifically, given that young people become highly invested in peer relationships during adolescence, it was anticipated that older participants would be more influenced by their peer relationships than younger participants. Therefore, it was theorized that 
stronger associations of appearance-RS with factors within the peer context would be found among older compared to younger participants. On the other hand, in light of the literature that suggests that parents may play a more influential role in relation to appearance concerns for their children in the earlier years (Lowes \& Tiggemann, 2003; Paxton et al., 2006), that stronger associations of appearance-RS with parent factors would be found among younger compared to older participants. No specific hypotheses were derived from past literature relating to age differences in the associations of appearance-RS with media influences.

Notably, measures were selected for or modified to have a focus on physical appearance that would relate to both male and female appearance ideals (e.g., they did not solely focus on weight and weight loss). This had the additional benefit of broadening the scope of measures beyond what might typically be assessed in relation to body dissatisfaction, thus capturing a wider range of physical aspects. It was expected that girls would report significantly higher levels of appearance-RS than boys, but no a priori predictions were made regarding gender differences in the associations of peer, family and media factors with appearance-RS.

\section{Method}

\section{Participants}

Participants were 365 students (55\% females) in grades 5, 6, or 7 attending one of three independent private schools in an urban area of Australia, encompassing low-middle to highmiddle socioeconomic status (SES). The proportion of participants in each grade (i.e., grade 5: 27\%; grade 6: 31\%; grade 7: 42\%) closely represented the proportions of students in each grade across the three schools. Participating students completed two questionnaires separated by one year. The original T1 sample included 387 students, but 6\% were not able to be located at T2. There were no differences in demographics or T1 measures between those who did, and those who did not complete the T2 assessment ( $p \mathrm{~s} \geq .11$ ). 
Students ranged in age from 9 to 14 years at T1 $\left(M_{\text {age }}=12.0, S D=0.90\right)$, with $99.5 \%$ of participants aged 10-13 years (2 students were age 9 and 1 was age 14). Almost all students were white/Caucasian (79\%) or reported Asian descent (15\%). One participant was of Australian Aboriginal or Torres Straight/Pacific Island descent. About 50\% of students returned parental consent forms to the schools, resulting in a participation rate of $42.4 \%$, with another $15.7 \%$ of parents declining their children's participation.

\section{Procedure}

Following receipt of approval from the university Human Research Ethics Committee, active parental consent was obtained for each participant. Students were given consent forms to take home and return to the school. To encourage the return of consent forms (regardless of parental consent to participate), a cupcake party was awarded to the class within each grade, at each school, that returned the most consent forms. The data presented in this study are drawn from a larger ongoing longitudinal study focused on appearance-RS. The present study is based on Waves 1 and 3 of this study, which were conducted 12 months apart. The portions of the questionnaire included in the present study were completed in approximately 30 minutes. Participating students received a small gift after each survey was completed. To reduce the burden on participants, all participants completed most measures, but three measures (internalization of media ideals, sociocultural pressure to be attractive and general-RS) were administered to only 50\% of the sample using a planned missingness design (Little, Jorgensen, Lang, \& Moore, 2014). The three measures not completed by all students were distributed across students (i.e., the same group of participants were not missing on all three measures), and there were no significant differences on any of the other variables between those who did or did not complete each of these measures (all $p>.05)$.

\section{Measures}


Appearance-RS. The Adolescent Appearance-RS Scale (Webb et al., 2014) was used to assess appearance-RS. Similar to the original scale that measured appearance-RS in adults (Park, 2007), participants were asked to imagine themselves in 10 hypothetical scenarios (e.g., "You are leaving your house to go to school when you notice a big pimple on your face”), and indicate on a 6-point scale their anxiety/concern about being rejected based on their appearance (e.g., "How concerned or anxious would you be that others would think you were less attractive because of the way you look?”; 1 = not concerned, 6 = very concerned), and their expectation of appearancerelated rejection in the imagined scenario (e.g., "Do you think other people would find you unattractive because of the way you look”; 1 = No!!, 6 = Yes!!). Anxious concern was multiplied by expectation of rejection for each item, and these 10 product scores were averaged to form the total score (Webb et al., 2014). The possible range for total scores was 1 to 36, and a higher score indicated greater appearance-RS. Cronbach’s $\alpha$ was .92 at T1 (.94 for girls, .85 for boys), and .93 at T2 (.93 for girls and .88 for boys).

Appearance teasing. A version of the Weight Teasing Subscale of the Perceptions of Teasing Scale (POTS; Thompson, Cattarin, Fowler, \& Fisher, 1995) modified to focus on appearance more generally (Webb et al., 2014) was used to measure appearance teasing from same-sex and other-sex peers (3 items) and parents (1 item). Example items are: "Do your parents tease you about your weight or looks?” and “Do people your age call you names because of your appearance?” Participants rated the frequency of the behavior $(1=$ never, $5=$ always $)$, and the degree to which the behavior was upsetting $(1=$ not upset, $5=$ very upset $)$. For the parent subscale, the frequency rating was multiplied by the distress rating. For the peer subscale, the product of the same-sex and opposite-sex frequency rating was multiplied by the distress rating, and averaged across the three items. The possible range for the total peer teasing score was 1 to 
125, and for parent teasing it was 1 to 25 . Higher scores indicated greater appearance teasing by peers or parents. For peer appearance teasing, Cronbach's $\alpha$ was .80 (.80 for girls, .79 for boys).

Pressure to be attractive. A version of the Perceived Sociocultural Pressure Scale (Stice \& Agras, 1998) used in previous research to focus on attractiveness and appearance, rather than pressure to be thin (Webb et al., 2014) was used. This measure assessed perceived pressure from same-sex and other-sex peers (4 items), family (2 items), and the media (2 items) to be attractive. An example item is: "I've felt pressure to look good from people in my family." Participants responded using a 5-point scale $(1=$ none, $5=a$ lot $)$. Averaging items formed total scores for peers (Cronbach’s $\alpha=.86$ for full sample, .88 for girls, .82 for boys), family (Cronbach’s $\alpha=.86$ for full sample, .90 for girls, .82 for boys), and the media (Cronbach’s $\alpha=.87$ for full sample, .86 for girls, .88 for boys). The possible range for each total score was 1 to 5 , and a higher score indicated greater perceived pressure from each source to be attractive.

Parents' negative appearance attitudes and eating behavior. The 3-item Attitude and Behavior Scale (Wood Baker et al., 2000) was used to assess perceptions of parents’ negative appearance-related attitudes behavior. An example item is: "My mum/dad worries about how they look” (1 = never, 5 = always). Adolescents were asked to report on their mother's and father's negative appearance attitudes if they had contact with that parent. Data on mother's and father's attitudes was reported by 362 and 352 adolescents, respectively. A total score was formed from averaging all six responses (three for each parent). Total scores could range from 1 to 5, and Cronbach’s $\alpha$ was .74 (.74 for girls, .75 for boys).

Appearance conversations with friends. The frequency of conversations with friends about appearance was assessed using the 6-item Appearance Conversations with Friends Scale (Jones et al., 2004). An example item is: “My friends and I talk about looking good through fitness 
and sport” $(1=$ never, 5 = very often $)$. Averaging items formed the total score, with a possible range of 1 to 5. A higher score indicated more frequent appearance conversations. Cronbach's $\alpha$ was .90 ( .90 for girls, .88 for boys).

Internalization of media ideals. Six items from The Sociocultural Attitudes Toward Appearance Questionnaire (SATAQ; Heinberg, Thompson, \& Stormer, 1995) modified so that items reflect both male and female appearance ideals (Webb et al., 2014), were used to assess internalization of media ideals ("I would like my body to look like the people who are in movies"; "I do not try to look like people on TV" - reversed). Reponses ranged from 1 (strongly disagree) to 5 (strongly agree). A total score was formed by averaging all items, with a possible range of 1 to 5. Cronbach’s $\alpha$ was .84 ( .85 for girls, .81 for boys).

BMI. Participant weight and height were measured at Time 1, during the session in which questionnaires were completed. With participant consent, measurements were taken individually and in private by a trained researcher, and used to calculate BMI (weight $\mathrm{kg} / \mathrm{height} \mathrm{m}^{2}$ ). BMI was then converted to percentiles according to participant age and gender, as per the Centers for Disease Control and Prevention norms.

General-RS. The 6-item Children's RS Questionnaire (Downey, Lebold, Rincon, \& Freitas, 1998) was used to assess general sensitivity to rejection. Six hypothetical scenarios were presented, for example; "Imagine you had a really bad fight the other day with a friend. Now you have a serious problem and you wish you had your friend to talk to. You decide to wait for your friend after class and talk with him/her. You wonder if your friend will want to talk to you.” Participants indicated on a 6-point scale, their anxiety about the outcome of each situation (e.g., "How NERVOUS would you feel, RIGHT THEN, about whether or not your friend will want to talk to you and listen to your problem?"; 1 = not nervous, 6 = very, very nervous), and how angry 
they feel about the possibility of being rejected (e.g., "How MAD would you feel, RIGHT THEN, about whether or not your friend will want to talk to you and listen to your problem?\|; $1=$ not mad, 6 = very, very mad). Finally, participants indicated their perceived likelihood that they will be accepted or rejected (e.g., "Do you think he/she will want to talk to you and listen to your problem?; 1 = YES!!, 6 = NO!!). Anxious expectation of rejection was scored by multiplying the participant's anxious concern with their expectation of rejection. Angry expectation of rejection was scored by multiplying the participant's anger score with their expectation of rejection. The total general-RS score was formed by averaging across anxious and angry expectations of rejection, with a total possible range of 1 to 36 (Downey et al., 1998). In this sample, Cronbach's $\alpha$ for the total general-RS scale was .74 (.81 for girls, .60 for boys).

Attractiveness. A peer-nominated attractiveness score was calculated for each participant, based on the procedure by Crick and Grotpeter (1995). From a list of all students in the same grade, participants were asked to nominate up to 10 classmates who he or she perceived to be "the most attractive.” Nominations received for each participating student were summed and standardized within grade.

\section{Overview of the Data Analyses}

To manage missing data, multiple imputation was used to estimate 10 imputed datasets, from which pooled means, $t$-tests and correlations between all variables were calculated. Average SEs across the 10 datasets are reported. MPlus software and SPSS (IBM Corporation) were then used to test the two models. The first model examined the unique associations of all measures at T1 with T1 appearance-RS, controlling for BMI percentile, general-RS, and peer-reported attractiveness. The second model examined the unique associations of all measures at T1 with T2 appearance-RS, controlling for T1 appearance-RS, BMI percentile, general-RS, and peer-reported 
attractiveness. We used four different strategies to fit these models to the datasets formed from multiple imputation in SPSS. First, we fit the path models using MPlus with maximum likelihood estimation for each of the 10 imputed datasets and pooled path estimates were calculated following procedures described in Allison (2003, see pages 550-552). Second, we first averaged scores for each participant for each measure across the 10 imputed datasets and fit the models to this single composite dataset. Third, we estimated regression models using SPSS to examine pooled parameter estimates to compare to the MPlus path model results. Fourth, we repeated the first two approaches using a Bayes estimator. Overall, the substantive results were quite similar across all of these methods and we report results from the first approach, given that these results were slightly more conservative. In each MPlus path model, all paths were freely estimated (including covariances between all T1 measures), so models had perfect fit to the data and no fit indices are reported (Hoyle, 2012).

To address gender differences, scores for boys and girls were compared using $t$-tests, and correlations were examined independently for boys and for girls. In addition, multiple group models were fit for each of the 10 imputed datasets, and final model estimates were formed by averaging the estimates derived from the imputed datasets. Multiple group models were fit to identify whether concurrent and prospective associations between sociocultural influence factors and appearance-RS differed between boys and girls, and between younger and older participants. Participants between the ages of 9.0 and 11.9 years formed a younger group $(n=170)$, and participants between the ages of 12 and 14 years formed the older group $(n=195) \cdot \chi^{2}$ difference tests were used to compare model fits before and after constraining model parameter estimates to be equal for boys and girls, or for younger and older participants (Kline, 2005).

\section{Results}




\section{Means, Standard Deviations, and Correlations}

Table 1 presents the Ms and SEs of all measures, and the correlations between all measures. As can be seen in Table 1, T1 and T2 appearance-RS were positively associated with each other and with all T1 sociocultural factors, except for pressure from family members, which was not associated with T2 appearance-RS. T1 and T2 appearance-RS were positively associated with BMI percentile and general-RS, but not peer-reported attractiveness. Age at T1 was associated with T2, but not T1, appearance-RS.

\section{Model 1: Concurrent Correlates of Appearance-RS at T1}

Model 1 was fit to test the unique, concurrent associations of all measures at T1 with T1 appearance-RS, controlling for BMI percentile, RS, and peer-reported attractiveness. The model explained a significant 59\% of the variance in T1 appearance-RS (95\% CI $=0.52-0.67$; see Table 2). Consistent with hypotheses regarding peers, parents, and the media, appearance-RS was found to be positively associated with appearance teasing by peers and parents, pressure to be attractive from peers, and internalization of media ideals. In addition, general-RS was positively associated with appearance-RS.

\section{Model 2: Prospective Correlates of Appearance-RS at T2}

Model 2 was fit to test the unique, prospective associations of all measures at T1 with T2 appearance-RS, controlling for T1 appearance-RS, BMI percentile, general-RS, and peer-reported attractiveness. The initial model appeared to be affected by a suppression effect, as family pressure and peer pressure to be attractive each showed moderate, negative (but nonsignificant) associations with T2 appearance-RS. As such, these two variables were removed and the model was refit to the data. The resulting model explained a significant $45 \%$ of the variance in $\mathrm{T} 2$ appearance-RS (95\% CI = 0.36 - 0.54; see Table 3). In this model, perceived parental appearance teasing and negative appearance attitudes at $\mathrm{T} 1$ were associated with greater relative increases in 
appearance-RS from T1 to T2. None of the peer or media factors, as well as none of the control variables, was uniquely associated with T2 appearance-RS in this model ( $p s>.05)$.

\section{The Unique Effects of Mother and Father Negative Attitudes}

Because 352 adolescents reported about the negative appearance-related attitudes of their mothers separate from their fathers (13 had no contact with a father), we conducted follow-up analyses to examine their unique contributions to T1 and T2 appearance-RS. Similar to what was found in the model of T1 appearance-RS shown in Table 2, neither mother attitudes nor father attitudes were significantly associated with T1 appearance-RS. In the prospective analyses, mother attitudes showed a significant positive association with T2 appearance-RS $(\beta=.10, p=.04)$. Father attitudes were not associated with T2 appearance-RS $(\beta=.02, p=.66)$.

\section{Age Effects}

Age differences. When younger (age 9 to $<12$ years, $n=170$ ) and older (age 12 to 14 years, $n=195$ ) participants were compared, two groups differences were found. Older participants $(M=1.94, S E=0.07)$ reported more appearance conversations with friends than younger participants $(M=1.65, S E=0.05), t(363)=-3.46, p=.001$, and older participants $(M=2.82, S E=$ $0.09)$ reported more internalization of media ideals than younger participants $(M=2.55, S E=$ $0.10), t(363)=-2.37, p=.02$.

Age moderation. Multiple group SEM (based on averaged estimates from models calculated from 10 imputed data sets) showed that the model fit when predicting T1 appearanceRS from T1 sociocultural and control factors did not differ when the structural paths (i.e., pathways between T1 and T2 measures) were constrained to equality for younger and older participants compared to when they were unconstrained, $\Delta \chi^{2}(11, N=365)=8.39, p=.68$. On the other hand, the model fit predicting T2 appearance-RS from T1 sociocultural and control factors 
did differ when the structural paths were constrained between younger and older participants as compared to unconstrained, $\Delta \chi^{2}(11, N=365)=31.93, p<.001$. In this model, there was one path that was found to produce a significant difference in model fit when unconstrained between younger and older participants. Specifically, the fit of the prospective model differed when the path from parent appearance attitudes and behaviors was unconstrained, $\Delta \chi^{2}(11, N=365)=8.17$, $p=.004$. Younger participants showed a positive association between T1 parent appearance attitudes and T2 appearance-RS $(\beta=.22,95 \% C I=0.07-0.36)$, while the association was not significant in older participants $(\beta=-.01,95 \% C I=-0.14-0.11)$. As such, the unique and positive association between T1 perceptions of negative parental appearance attitudes and T2 appearanceRS was specific to younger ( 9 - 11 years), but not older participants (12 - 14 years).

\section{Gender Effects}

Gender differences. Table 4 presents the Ms, SEs, and correlations between all measures, for boys separate from girls. T1 and T2 appearance-RS were positively associated with T1 sociocultural influence variables among both boys and girls, except for the association between T2 appearance-RS and media factors (internalization and media pressure), which was not significant in boys. Girls compared to boys reported higher levels of appearance-RS and all peer and media influences. Boys and girls did not differ when comparing parent appearance teasing, parent attitudes, family pressure, BMI percentile, general-RS and peer-reported attractiveness.

Gender moderation. Multiple group SEM showed that the model fit predicting T1 appearance-RS from T1 sociocultural and control factors did not differ when the structural paths of a model constrained to equality for boys and girls was compared to a model that was unconstrained, $\Delta \chi^{2}(11, N=365)=14.41, p=.21$. Similarly, the model fit predicting T2 appearance-RS from T1 sociocultural and control factors did not differ when the structural paths 
were constrained compared to unconstrained between boys and girls, $\Delta \chi^{2}(11, N=365)=10.58, p$ $=.48$. In sum, despite differences in reported levels of appearance-RS and all peer and media influences, there was no indication that the concurrent or prospective associations between sociocultural factors and appearance-RS differed between boys and girls.

\section{Discussion}

Past research has identified the potentially influential role of messages, modeling of appearance-related behaviors, and direct pressures within one’s peer group and family for the development of appearance-RS during adolescence (Webb et al., 2014) and adulthood (Park et al., 2009). Other research draws attention to the critical role of media in appearance-related concerns (Menzel et al., 2011; Paxton et al., 2006; Stice \& Whitenton, 2002). The findings of the present study support the importance of all three of these sociocultural influences as correlates of young adolescents' elevated appearance-RS, especially when examined in the concurrent analysis. Thus young adolescents' concerns about rejection because of their appearance are more elevated when they perceive a greater focus on appearance and high salience of appearance among their peers, their parents, and the media more generally. Such salience is communicated either via teasing or via less direct and less directly negative means.

Participants were also followed for one year providing the ability to move beyond a snapshot of associations at one point in time, which has been most common in past research. In prospective analyses, parents seemed to be more influential and this was especially true for younger ( 9 - 11 years) compared to older (12 - 14 years) adolescents. Moreover, boys and girls were compared. Although girls perceived more appearance pressures and reported greater appearance-RS than boys, no differences were found in associations according to gender.

\section{Peers and the Media}


Friends and peers have often been described as highly salient social contexts to which adolescents are exposed on a daily basis (e.g., Hartup, 1993), whereas images in the media (and social media in particular) are increasingly attracting young people’s time and attention (Livingstone, 2008). The particular relevance of peers and the media for adolescent appearance concerns is well accepted, whereby these influential contexts are thought to provide a platform for transmitting salient appearance messages and for reinforcing appearance ideals and associated behaviors (Tiggemann \& Slater, 2013; Webb \& Zimmer-Gembeck, 2014). Our findings support these notions. In our analyses of the T1 data only (controlling for general-RS, BMI percentile, and peer-reported attractiveness), adolescents’ perceived pressure to conform to appearance ideals from peers and internalization of media ideals had positive associations with concerns about appearance-based rejection. In addition, perceived teasing about appearance by peers was also positively associated with appearance-RS in this concurrent model. These findings align with one existing cross-sectional study that simultaneously examined peer, parent and media influences, and found that appearance-RS was higher in young adults who reported greater internalization of media ideals (Park et al., 2009). Moreover, the present findings are consistent with a study of the peer appearance culture among early adolescents, which found peer appearance teasing and perceived pressure to be attractive from peers to be uniquely and concurrently associated with appearance-RS (Webb et al., 2014). Peers and media images represent salient sources of appearance-related information and influence to which adolescents are exposed on a daily basis, and which are being increasingly shown to impact on conceptions of self, including appearance beliefs (Jones et al., 2004).

\section{Parents and Age Effects}

Parents' behaviors, as perceived by their adolescent offspring, had significant and unique roles in appearance-RS in both our concurrent and prospective analyses. Consistent with the 
theory that RS develops from a history of real or perceived rejection experiences (Downey \& Feldman, 1996; Downey et al., 1997), appearance teasing by parents showed a unique positive association with appearance-RS assessed concurrently, and one year later. In conjunction with previous cross-sectional evidence of the direct positive association between peer appearance teasing and appearance-RS (Webb et al., 2014), and experimental research showing that appearance-RS sufferers report feeling alone and rejected after recalling a negative appearance comment (Park, Calogero et al., 2009), we theorize that appearance teasing may transmit powerful messages about appearance ideals, in addition to conveying interpersonal rejection specifically tied to appearance, thus correlating with elevated adolescent concerns about appearance-based rejection. In addition to the association of appearance teasing by parents with appearance-RS, adolescents also had more elevated appearance-RS at T2 relative to T1 when they reported greater parental modeling (and in particular, modeling from mothers) of negative appearance attitudes. Thus, it was parental behaviors that figured most prominently as correlates of increases in adolescents' appearance-RS over time. The concurrent role of peers and the media for appearanceRS in contrast to the prospective role of parents, can be understood from the perspective that while peers and media represent popular, topical and evolving sources of influence for a young person, the family context is typically more proximal, protracted and stable, and as such may have the greatest opportunity for shaping beliefs and behaviors over longer periods of time. Another possibility is that teasing by peers may be more overt and clearly expressed, resulting in a more immediate impact on appearance-RS when compared to the influence of teasing and modeling by parents, which may be more subtle and take more time to influence adolescents' sensitivity to rejection.

Notably, and consistent with expectations, it was younger adolescents aged between 9 and 11 years, in particular, that reported increases in appearance-RS over 12 months following reports 
that their parents more frequently demonstrate negative appearance attitudes. This association was not significant in older participants (i.e., aged between 12 and 14 years). These findings align with previous research that has found parents play a formative role in relation to their children's body image attitudes and eating behaviors, particularly during childhood - and the present study provides evidence that this may continue into the early years of adolescence - but that the influence of parents in relation to appearance concerns may decline into middle adolescence (Lowes \& Tiggemann, 2003; Paxton et al., 2006; Ricciardelli \& McCabe, 2001). This declining influence of parents may be due to the normative adolescent process of increasing time spent and connectedness with friends and peers, in conjunction with growing individuation, self-reliance, and autonomy from parents (Steinberg \& Morris, 2001; Zimmer-Gembeck \& Collins, 2003). It may also be that the physical changes experienced during adolescence prompt young people to increasingly look to their peers who are undergoing similar changes, rather than to family members, for support and information about appearance ideals and grooming (Paikoff \& BrooksGunn, 1991). The family represents a complex, dynamic and immediate context in which a child learns (Lerner, 2013), and suggests that young people are cognizant and receptive to appearancefocused messages within their peer relationships and the media, but in early adolescence, it is parental modeling of appearance attitudes, and appearance-related teasing by parents that seem to impact on appearance-RS at a later point in time.

\section{Gender Effects}

Previous research has found that concerns about appearance-based rejection tend to be higher in young women than young men (Park et al., 2009), and our findings confirm this for girls compared to boys. We also tested whether the associations of appearance-RS with the multiple

peer, family and media influences measured here would differ between boys and girls, but no differences were found, which is consistent with past research (Park et al., 2009; Webb et al., 
2014; Webb \& Zimmer-Gembeck, 2014). As such, it appears that the role of the socio-cultural risk factors for appearance-RS is similar for boys and girls. Despite this finding, continued consideration of gender in research on appearance and body image is important. There is a changing media climate for boys and men, and visual appearance ideals have become more and more unattainable for both sexes in recent years (Hatoum \& Belle, 2004; Homan, 2010; Michaels, Parent, \& Moradi, 2013). Portrayals of beauty and attractiveness standards in the media, as well as the high values adolescents place on the media and their peer and family relationships (Allen et al., 2014; Madden et al., 2013) seem perfect for setting the stage for appearance-RS when these contexts are perceived to provide more pressure about conforming to appearance ideals.

\section{Limitations, Implications and Conclusion}

We must caution that most measures were self-report (the exceptions being researchermeasured BMI and peer-reported attractiveness), placing the results at risk of shared method variance. We encourage future research that includes data gathered from multiple reporters. For example, incorporating assessments of parents' reported beliefs and attitudes would isolate the role of parental beliefs from adolescents’ perceptions of their parents' attitudes, beliefs and behaviors. Second, items used to assess media influences used the word "media” to refer to a range of possible media sources, rather than specifying specific sources of influence (e.g., "I’ve felt pressure to look good from the media”), which may have prevented a full and accurate assessment of media influences currently experienced by young people. Popular forms of media currently include social media platforms, which reflect a crossover between peer and media influences, blurring the lines between these previously distinct sociocultural sources. Given the centrality of social media in young people’s lives, and the personalized and idealized content of this medium, future research would benefit from a more comprehensive assessment of media exposure that better encapsulates the many forms of visual media that are easily available. 
Other limitations to raise are the timing of the measurement of height and weight, the response rate, lack of pubertal data, and the measure of general-RS in boys. Measuring participants' height and weight during the session in which they completed the questionnaire may have primed appearance-related concerns, potentially resulting in elevations in reported appearance-RS. It is notable that only a very small number of students $(n=5)$ voiced concern about having their weight measured (these students were excused from measurements). The response rate of this study was lower than preferred (42.4\%), potentially limiting the generalizability of results, and data on pubertal development was not assessed. The internal consistency of the 6-item general-RS measure was low among boys, suggesting that this measure may be less reliable for adolescent boys than girls. It may be that the items, which predominantly focused on being selected by one's teacher for a special privilege, or being helped or chosen by classmates, may be less salient contexts for RS among early adolescent boys. Future research could address whether RS may present differently in boys compared to girls.

In addition, the present findings have a number of implications. First, these results highlight the continuing importance of the family environment in socializing appearance attitudes beyond childhood into early adolescence. Researchers have previously advocated that the family environment represents a salient source of influence for children’s eating and body image concerns (Rodgers et al., 2009), and highlights the importance of parents in considering their own body image and eating behaviors, teasing about appearances among family members, and the message these interactions convey to children. Conversely, these findings also provide hope that while we cannot always protect our children from exposure to idealized and unhelpful appearance messages spread throughout the media and children's social groups, providing a positive home environment that emphasizes and models healthy appearance attitudes and refrains from appearance teasing appears to be protective of concerns about appearance-based rejection over 
time, during childhood and at least into the early years of adolescence. Relatedly, drawing upon the literature on the appearance culture within adolescent peer groups (Clark \& Tiggemann, 2006; Jones, 2004), consideration of the appearance culture in the family context might be useful in understanding the many inadvertent and possibly well-intentioned interactions that may act to strengthen unhelpful attitudes about appearance. Second, these findings suggest the importance of targeting all sociocultural sources, including the family environment, in interventions for adolescent appearance concerns. This suggestion aligns with widely supported treatment approaches that utilize the family system to address extreme body image concerns and eating disorders (Eisler et al., 2000), as well as problems with children’s eating and weight management (Sung-Chan, Sung, Zhao, \& Brownson, 2013) and mood disorders (Miklowitz et al., 2013). Future research that examines mother and father influences on adolescents' appearance beliefs at this critical time of development, and beyond, is warranted in order to further elucidate the mechanisms underlying the associations found in the current study.

In summary, appearance-related pressures from parents, peers and the media, and appearance-related interactions between young adolescents and their peers or parents, are each uniquely relevant and salient for identifying boys and girls with concurrent, elevated levels of appearance-RS. In addition, parents' teasing about appearance play a particular role in predicting when adolescents, especially young people just transitioning into adolescence, show a greater relative increase in their appearance-RS over the next year. These findings support the Tripartite Social Influences Model (Thompson et al., 1999) when applied to appearance-RS, and emphasize the significance of "pretty pressure” experienced within peer, family and media contexts. These findings also highlight the role of the family environment especially in young people just transitioning into adolescence, whereby family behaviors play a role in appearance concerns. More generally, however, these findings suggest that there is an important role for the family in 
minimizing the adverse and salient sociocultural messages about physical attractiveness to which adolescents are exposed on a daily basis, through parental modeling and facilitation of adaptive eating behaviors and positive appearance-focused attitudes and inter-family interactions. 


\section{References}

Allen, K. A., Ryan, T., Gray, D. L., McInerney, D. M., \& Waters, L. (2014). Social media use and social connectedness in adolescents: The positive sand the potential pitfalls. The Australian Educational and Developmental Psychologist, 31, 18-21. doi:10.1017/edp.2014.2

Azmitia, M. (2003). Self, self-esteem, conflicts, and best friendships in early adolescence. In T. M. Brinthaupt \& R. P. Lipka (Eds.), Understanding early adolescent self and identity: Applications and interventions (pp. 167-192). New York: State University of New York Press.

Baker, C. W. Whisman, M.A. \& Brownell, K.D. (2000). Studying intergenerational transmission of eating attitudes and behaviors: Methodological and conceptual questions, Health Psychology, 19, 376-381. doi:10.1037/0278-6133.19.4.376

Bandura, A. (1977). Social Learning Theory. Englewood Cliffs, NJ: Prentice Hall.

Baumeister, R. F., \& Leary, M. R. (1995). The need to belong: Desire for interpersonal attachments as a fundamental human motivation. Psychological Bulletin, 117, 497-529.

Bearman, S. K., Presnell, K., Martinez, E., \& Stice, E. (2006). The skinny on body dissatisfaction: A longitudinal study of adolescent girls and boys. Journal of Youth and Adolescence, 35, 217-229. doi:10.1007/s10964-005-9010-9

Bove, C. F., \& Sobal, J. (2011). Body weight relationships in early marriage: Weight relevance, weight comparisons, and weight talk. Appetite, 57, 729-742. doi:10.1016/j.appet.2011.08.007

Bowker, J. C., Thomas, K. K., Spencer, S. V., \& Park. L. E. (2013). Examining appearance-based rejection sensitivity during early adolescence. Journal of Research on Adolescence, 23, 375-388. doi:†1.1111/jora.12003

Bukowski, W. M., Newcomb, A. F., \& Hartup, W. W. (1998). The company they keep: 
Friendships in childhood and adolescence. Cambridge, UK: Cambridge University Press.

Butler, J. C., Doherty, M. S., \& Potter, R. M. (2007). Social antecedents and consequences of interpersonal rejection sensitivity. Personality and Individual Differences, 43, 1376-1385. doi:10.1016/j.paid.2007.04.006

Clark, L., \& Tiggemann, M. (2006). Appearance culture in nine- to 12-year-old girls: Media and peer influences on body dissatisfaction. Social Development, 15, 628-643. doi:10.1111/j.1467-9507.2006.00361.x

Clark, L. \& Tiggemann, M. (2008). Sociocultural and individual psychological predictors of body image in young girls: a prospective study. Developmental Psychology, 44, 11241134. doi:10.1037/0012-1649.44.4.1124

Collins, W. A., \& Laursen, B. (2004a). Changing relationships, changing youth: Interpersonal contexts of adolescent development. The Journal of Early Adolescence, 24, 55-62. doi:10.1177/0272431603260882

Collins, W. A., \& Laursen, B. (2004b). Parent-adolescent relationships and influences. In R. M. Lerner \& L. Steinberg (eds.), Handbook of Adolescent Psychology, Second Edition. John Wiley \& Sons, Inc., Hoboken, NJ, USA. doi:10.1002/9780471726746.ch11

Crick, N. R., \& Grotpeter, J, K. (1995). Relational aggression, gender, and social-psychological adjustment. Child Development, 66, 710-722. doi: 10.1111/j.1467-8624.1995.tb00900.x

Downey, G., Bonica, C., \& Rincon, C. (1999). Rejection sensitivity and conflict in adolescent romantic relationships. In W. Furman, B. Brown, \& C. Feiring (Eds.), The development of adolescent romantic relationships (pp. 148-174). New York: Cambridge University Press.

Downey, G. \& Feldman, S. I. (1996). Implications of rejection sensitivity for intimate relationships. Journal of Personality and Social Psychology, 70, 1327-1343. doi:10.1037/0022-3514.70.6.1327 
Downey, G., Khouri, H., \& Feldman, S. (1997). Early interpersonal trauma and adult adjustment: The mediational role of rejection sensitivity. In D. Cicchetti \& S. Toth (eds.), Rochester Symposium on Developmental Psychopathology, Volume VIII (pp. 85-114). New York: University of Rochester Press.

Downey, G., Lebold, A., Rincon, C., \& Freitas, A. L. (1998). Rejection sensitivity and children’s interpersonal difficulties. Child Development, 69, 1074-1091.

Eisenberg, M. E., Neumark-Sztainer, D., \& Paxton, S. J. (2006). Five-year change in body satisfaction among adolescents. Journal of Psychosomatic Research, 61, 521-527. doi: 10.1016/j.jpsychores.2006.05.007

Eisler, I., Dare, C., Hodes, M., Russell, G., Dodge, E., \& Le Grange, D. (2000). Family therapy for adolescent anorexia nervosa: The results of a controlled comparison of two family interventions. The Journal of Child Psychology and Psychiatry and Allied Disciplines, 41, 727-736. doi:10.1017/S0021963099005922

Fildes, J., Robbins, A., Cave, L., Perrens, B. \& Wearring, A. (2014). Mission Australia’s 2014 Youth Survey Report, Mission Australia. Retrieved from: https://www.missionaustralia.com.au/publications/research/young-people?view=docman Fredrickson, B., \& Roberts, S. (1997). Objectification theory: Toward understanding women’s lived experiences and mental health risks. Psychology of Women Quarterly, 21,173-206.

Frisén, A., Lunde, C., Berg, A. I. (2015). Developmental patterns in body esteem from late childhood to young adulthood: A growth curve analysis. European Journal of Developmental Psychology, 12, 99-115. doi:10.1080/17405629.2014.951033

Furman, W., Brown, B. B., \& Feiring, C. (Eds.), (1999). The development of romantic relationships in adolescence. New York: Cambridge University Press.

Furman, W., \& Buhrmester, D. (1992). Age and sex differences in perceptions of networks of 
personal relationships. Child Development, 63, 832-837.

Hampshire, A., di Nicole, K., Buckley, H., French, G. \& Fildes, J. (2010). Mission Australia’s 2014 Youth Survey Report, Mission Australia. Retrieved from:

https://www.missionaustralia.com.au/publications/research/young-people?view=docman

Harter, S. (1999). The construction of the self: A developmental perspective. New York: Guilford Press.

Hartup, W. W. (1993). Adolescents and their friends. New Directions for Child Development, 60, 3-22.

Hatoum, I. J., \& Belle, D. (2004). Mags and abs: Media consumption and bodily concerns in men. Sex Roles, 51, 397-407. doi:10.1023/B:SERS.0000049229.93256.48

Heinberg, L. J., Thompson, J. K., \& Stormer, S. (1995). Development and validation of the Sociocultural Attitudes Towards Appearance Questionnaire. International Journal of Eating Disorders, 17, 81-89. doi:10.1002/1098-108X(199501)17:1<81::AIDEAT2260170111>3.0.CO;2-Y

Helfert, S., \& Warschburger, P. (2013). The face of appearance-related social pressure: Gender, age and body mass variations in peer and parental pressure during adolescence. Child \& Adolescent Psychiatry \& Mental Health, 7, 16-26. doi:10.1186/1753-2000-7-16

Homan, K. (2010). Athletic-ideal and thin-ideal internalization as prospective predictors of body dissatisfaction, dieting, and compulsive exercise. Body Image, 7, 240-245. doi:10.1016/j.bodyim.2010.02.004

Hoyle, R. H. (2012). Handbook of structural equation modeling (1st ed.). New York: Guilford Publications.

Hyde, A., Cillessen, A. H. N., \& Borch, C. (2011). The role of attractiveness and aggression in high school popularity. Social Psychology of Education, 14, 23-39. doi:10.1007/s11218- 
010-9131-1

Jones, D. C. (2004). Body image among adolescent girls and boys: A longitudinal study. Developmental Psychology, 40, 823-835. doi:10.1037/0012-1649.40.5.823

Jones, D. C., Vigfusdottir, T. H., \& Lee, Y. (2004). Body image and the appearance culture among adolescent girls and boys: An examination of friend conversations, peer criticism, appearance magazines, and the internalization of appearance ideals. Journal of Adolescent Research, 19, 323-339. doi:10.1177/0743558403258847

Keery, H., van den Berg, P., \& Thompson, J. K. (2004). An evaluation of the tripartite influence model of body dissatisfaction and eating disturbance with adolescent girls. Body Image, 1, 237-251. doi:10.1016/j.bodyim.2004.03.001

Kline, R. B. (2005). Principles and practice of structural equation modeling $\left(2^{\text {nd }}\right.$ ed.). New York: Guildford Press.

Kluck, A. S. (2010). Family influence on disordered eating: The role of body image dissatisfaction. Body Image, 7, 8-14. doi:10.1016/j.bodyim.2009.09.009

Lerner, R. M. (2013). Individual development and the family system: A life-span perspective. In K. Kreppner \& R. M. Lerner (Eds.) Family Systems and Life-Span Development. Psychology Press.

Littleton, H. L., \& Ollendick, T. (2003). Negative body image and disordered eating behavior in children and adolescents: What places youth at risk and how can these problems be prevented? Clinical Child and Family Psychology Review, 6, 51-66. doi:10.1023/A:1022266017046

Livingstone, S. (2008). Taking risky opportunities in youthful content creation: Teenagers' use of social networking sites for intimacy, privacy and self-expression. New Media \& Society, 10, 393-411. doi:10.1177/1461444808089415 
Lowes, J., \& Tiggemann, M. (2003). Body dissatisfaction, dieting awareness and the impact of parental influence in young children. British Journal of Health Psychology, 8, 135-147. doi:10.1348/135910703321649123

MacBrayer, E. K., Smith, G. T., McCarthy, D. M., Demos, S., \& Simmons, J. (2001). The role of family of origin food-related experiences in bulimic symptomatology, International Journal of Eating Disorders, 30, 149-160.

Madden, M., Lenhart, A., Cortesi, S., Gasser, U., Duggan, M., Smith, A., \& Beaton, M. (2013, May 21). Teens, social media, and privacy. Pew Internet \& American Life Project. Retrieved from: http:// www.pewinternet.org/Reports/2013/Teens-Social-Media-AndPrivacy/Main-Report/Part-1.aspx

McCreary, D. R., \& Sasse, D. K. (2000). An exploration of the drive for muscularity in adolescent boys and girls. Journal of American College Health, 48, 297-305.

Menzel, J. E., Krawczyk, R., \& Thompson, J. K. (2011). Attitudinal assessment of body image for adolescents and adults. In: T. F. Cash \& L. Smolak, (Eds.), Body image: A handbook of science, practice, and prevention (pp. 154-169). New York: The Guilford Press.

Michaels, M., Parent, M. \& Moradi, B. (2013). Does exposure to muscularity-idealizing images have self-objectification consequences for heterosexual and sexual minority men? Psychology of Men \& Masculinity, 14, 175-183. doi:10.1037/a0027259

Miklowitz, D. J., Schneck, C. D., Singh, M. K., Taylor, D. O., George, E. L., Cosgrove, V. E., ...Chang, K. D. (2013). Early intervention for symptomatic youth at risk for bipolar disorder: A randomized trial of family-focused therapy. Journal of the American Academy of Child and Adolescent Psychiatry, 52, 121-131. doi:10.1016/j.jaac.2012.10.007

O'Keeffe, G., Clarke-Pearson, K., \& Council Communications and Media. (2011). Clinical reportthe impact of social media on children, adolescents, and families. Pediatrics, 127, 800-804. 
doi:10.1542/peds.2011-0054

Paikoff, R. L., \& Brooks-Gunn, J. (1991). Do parent-child relationships change during puberty? Psychological Bulletin, 110, 47-66. doi:10.1037/0033-2909.110.1.47

Park, L. E. (2007). Appearance-based rejection sensitivity: Implications for mental and physical health, affect, and motivation. Personality and Social Psychology Bulletin, 33, 490-504. doi:1.1177/0146167206296301

Park, L. E., Calogero, R. M., Harwin, M. J., \& DiRaddo, A. M. (2009). Predicting interest in cosmetic surgery: Interactive effects of appearance-based rejection sensitivity and negative appearance comments. Body Image, 6, 186-193. doi:10.1016/j.bodyim.2009.02.003

Park, L. E., Calogero, R. M., Young, A. F., \& DiRaddo, A. M. (2010). Appearance-based rejection sensitivity predicts body dysmorphic disorder symptoms and cosmetic surgery acceptance. Journal of Social and Clinical Psychology, 29, 489-509. doi:10.1521/jscp.2010.29.5.489

Park, L. E., DiRaddo, A. M., \& Calogero, R. M. (2009). Sociocultural influence and appearancebased rejection sensitivity among college students. Psychology of Women Quarterly, 33, 108-119. doi:1.1111/j.1471-6402.2008.01478.x

Park, L. E., \& Pinkus, R. E. (2009). Interpersonal effects of appearance-based rejection sensitivity. Journal of Research in Personality, 43, 602-612. doi:10.1016/j.jrp.2009.02.003.

Perrens, B., Robbins, A., Fildes, J., Ivancic, L., Wearring, A., \& Cave, L. (2013). Mission Australia’s 2013 Youth Survey Report, Mission Australia. Retrieved from: https://www.missionaustralia.com.au/publications/research/young-people?view=docman Paxton, S. J., Eisenberg, M. E., \& Neumark-Sztainer, D. (2006). Prospective predictors of body dissatisfaction in adolescent girls and boys: A five-year longitudinal study. Developmental Psychology, 42, 888-899. doi:10.1037/0012-1649.42.5.888 
Presnell, K., Bearman, S. K., \& Stice, E. (2004). Risk factors for body dissatisfaction in adolescent boys and girls: A prospective study. International Journal of Eating Disorders, 36, 389-401. doi:10.1002/eat.20045

Ricciardelli, L. A., \& McCabe, M. P. (2001). Children's body image concerns and eating disturbance: A review of the literature. Clinical Psychology Review, 21, 325.

Ricciardelli, L. A., \& McCabe, M. P. (2007). Pursuit of muscularity among adolescents. In J. K. Thompson, \& G. Cafri (Eds.), The muscular ideal: Psychological, social and medical perspectives (pp. 199-216). Washington, DC: American Psychological Association.

Rideout, V. J., Foehr, U. G., \& Roberts, D. F. Generation M: Media in the lives of 8- to 18-yearolds. https://kaiserfamilyfoundation.files.wordpress.com/2013/01/generation-m-media-inthe-lives-of-8-18-year-olds-report.pdf

Robins, R. W., \& Trzesniewski, K. H. (2005). Self-esteem development across the lifespan. Current Directions in Psychological Science, 14, 158-162. doi:10.1111/j.09637214.2005.00353.x

Rodgers, R., Chabrol, H., \& Paxton, S. J. (2011). An exploration of the tripartite influence model of body dissatisfaction and disordered eating among Australian and French college women. Body Image, 8, 208-215. doi:10.1016/j.bodyim.2011.04.009

Rodgers, R. F., Paxton, S. J., \& Chabrol, H. (2009). Effects of parental comments on body dissatisfaction and eating disturbance in young adults: A sociocultural model. Body Image, 6, 171-177. doi:10.1016/j.bodyim.2009.04.004

Rumsey, N., \& Harcourt, D. (2005). The psychology of appearance. New York; Maidenhead, England: Open University Press.

Shroff, H., \& Thompson, J. K. (2006). The tripartite influence model of body image and eating disturbance: A replication with adolescent girls. Body Image, 3, 17-23. 
doi:10.1016/j.bodyim.2005.10.004

Steinberg, L., \& Morris, A. S. (2001). Adolescent development. Annual Review of Psychology, 52, 83-110. doi:10.1146/annurev.psych.52.1.83

Stice, E. (1994). Review of the evidence for a sociocultural model of bulimia nervosa and an exploration of mechanisms of action. Clinical Psychology Review, 14, 633-661.

Stice, E. (2003). Puberty and body image. In C. Hayward (Ed.). Gender differences at puberty (pp. 61-76). Cambridge, UK: Cambridge University Press

Stice, E., \& Agras, W. S. (1998). Predicting onset and cessation of bulimic behaviors during adolescence: A longitudinal grouping analysis. Behavior Therapy, 29, 257-276. doi:10.1016/S0005-7894(98)80006-3

Stice, E., \& Whitenton, K. (2002). Risk factors for body dissatisfaction in adolescent girls: A longitudinal investigation. Developmental Psychology, 38, 669-678. doi:10.1037//00121649.38.5.669

Sung-Chan, P., Sung, Y. W., Zhao, X., \& Brownson, R. C. (2013). Family-based models for childhood-obesity intervention: A systematic review of randomized controlled trials. Obesity Reviews, 14, 265-278. doi:10.1111/obr.12000

Thompson, J. K., Cattarin, J., Fowler, B., \& Fisher, E. (1995). The Perception of Teasing Scale (POTS): A revision and extension of the Physical Appearance Related Teasing Scales (PARTS). Journal of Personality Assessment, 65, 146-157. doi:10.1207/s15327752jpa6501_11

Thompson, J. K., Heinberg, L. J., Altabe, M., \& Tantleff-Dunn, S. (1999). Exacting beauty: Theory, assessment and treatment of body image disturbance. Washington, DC: American Psychological Association.

Thompson, J. K., Shroff, H., Herbozo, S., Cafri, G., Rodriguez, J., \& Rodriguez, M. (2007). 
Relations among multiple peer influences, body dissatisfaction, eating disturbance, and self-esteem: A comparison of average weight, at risk of overweight, and overweight adolescent girls. Journal of Pediatric Psychology, 32, 24-29. doi:10.1093/jpepsy/jsl022

Thompson, J. K., \& Stice, E. (2001). Thin-ideal internalization: Mounting evidence for a new risk factor for body-image disturbance and eating pathology. Current Directions in Psychological Science, 10, 181-183. doi:10.1111/1467-8721.00144

Tiggemann, M., Gardner, M., \& Slater, A. (2000). "I would rather be size 10 than have straight A's": A focus group study of adolescent girls' wishes to be thinner. Journal of Adolescence, 23, 645-659. doi:10.1006/jado.2000.0350

Tiggemann, M., \& Slater, A. (2013). Netgirls: The internet, Facebook and body image concern in adolescent girls. International Journal of Eating Disorders, 46, 630-633. doi:10.1002/eat.22141

van den Berg, P., Thompson, J. K., Obremski-Brandon, K., \& Coovert, M. (2002). The tripartite influence model of body image and eating disturbance: A covariance structure modeling investigation testing the mediational role of appearance comparison. Journal of Psychosomatic Research, 53, 1007-1020. doi:10.1016/S0022-3999(02)00499-3

Vincent, M. A., \& McCabe, M. P. (2000). Gender differences among adolescents in family and peer influences on body dissatisfaction, weight loss, and binge eating behaviors. Journal of Youth and Adolescence, 29, 205-221. doi:10.1023/A:1005156616173

Webb, H. J., \& Zimmer-Gembeck, M. J. (2014). The role of friends and peers in adolescent body dissatisfaction: A review and critique of 15 years of research. Journal of Research on Adolescence, 24, 564-590. doi:10.1111/jora.12084

Webb, H. J., \& Zimmer-Gembeck, M. J. (2015). Body image and body change strategies within friendship dyads and groups: Implications for adolescent appearance-based rejection 
sensitivity. Social Development, 24, 1-19. doi:10.1111/sode.12081

Webb, H. J., Zimmer-Gembeck, M. J., \& Donovan, C, L. (2014). The appearance culture between friends and adolescent appearance-based rejection sensitivity. Journal of Adolescence, 37, 347-358. doi:10.1016/j.adolescence.2014.02.008.

Wertheim, E. H., Paxton, S. J., \& Blaney, S. (2004). Risk factors for the development of body image disturbances. In J. K. Thompson (Ed.), Handbook of eating disorders and obesity (pp. 695-717). Hoboken, N.J: Wiley.

Wood Baker, C., Whisman, M. A., \& Brownell, K. D. (2000). Studying intergenerational transmission of eating attitudes and behaviors: Methodological and conceptual questions. Health Psychology, 19, 376-381. doi:10.1037/0278-6133.19.4.376

Zimmer-Gembeck, M. J. (1999). Stability, change, and individual differences in involvement with friends and romantic partners among adolescent females. Journal of Youth and Adolescence, 28, 419-438. doi:10.1023/A:1021612907073

Zimmer-Gembeck, M. J. (2002). The development of romantic relationships and adaptations in the system of peer relationships. Journal of Adolescent Health, 31, 216-225.

Zimmer-Gembeck, M.J., \& Collins, W.A. (2003). Autonomy development during adolescence. In G.R. Adams \& M. Berzonsky (Eds.), Blackwell Handbook of adolescence (pp. 175204). Oxford: Blackwell Publishers.

Zimmer-Gembeck, M. J., \& Nesdale, D. (2013). Anxious and angry rejection sensitivity, social withdrawal, and retribution in high and low ambiguous situations. Journal of Personality, 81, 29-38. doi:10.1111/j.1467-6494.2012.00792.x

Zimmer-Gembeck, M. J., Siebenbruner, J., \& Collins, W. A. (2001). Diverse aspects of dating: Associations with psychosocial functioning from early to middle adolescence. Journal of Adolescence, 24, 313-336. doi:10.1006/jado.2001.0410 


\section{Table 1}

Means, Standard Deviations, and Correlations Between All Variables $(N=365)$

\begin{tabular}{|c|c|c|c|c|c|c|c|c|c|c|c|c|c|c|}
\hline Variables & 1 & 2 & 3 & 4 & 5 & 6 & 7 & 8 & 9 & 10 & 11 & 12 & 13 & 14 \\
\hline 1. Appearance-RS T1 & -- & & & & & & & & & & & & & \\
\hline 2. Appearance-RS T2 & $.63^{* *}$ & -- & & & & & & & & & & & & \\
\hline 3. Peer app conversations & $.44^{* *}$ & $.37 * *$ & -- & & & & & & & & & & & \\
\hline 4. Peer app teasing & $.49 * *$ & $.35^{* *}$ & $.23^{* *}$ & -- & & & & & & & & & & \\
\hline 5. Peer app pressure & $.62 * *$ & $.43^{* *}$ & $.57 * *$ & $.43^{* *}$ & -- & & & & & & & & & \\
\hline 6. Parent app teasing & $.44^{* *}$ & $.40^{* *}$ & $.26 * *$ & $.43^{* *}$ & .34 & -- & & & & & & & & \\
\hline 7. Family app pressure & $.34^{* *}$ & $.20 *$ & $.28 * *$ & $.30 * *$ & $.42^{* *}$ & .29 & -- & & & & & & & \\
\hline 8. Parent app attitudes & $.25^{* *}$ & $.28^{* *}$ & $.24^{* *}$ & $.20 * *$ & $.26^{* *}$ & $.23^{* *}$ & $.28^{* *}$ & -- & & & & & & \\
\hline 9. Media pressure & $.51^{* *}$ & $.34 * *$ & $.44^{* *}$ & $.37^{* *}$ & $.65^{* *}$ & .32 & $.42^{* *}$ & $.25^{* *}$ & -- & & & & & \\
\hline 10. Intern media ideals & $.50 * *$ & $.34^{* *}$ & $.47^{* *}$ & $.31^{* *}$ & $.48^{* *}$ & .23 & $.19^{*}$ & $.26^{* *}$ & $.52 * *$ & -- & & & & \\
\hline 11. BMI percentile & $.16^{* *}$ & $.18^{* *}$ & .10 & $.16^{* *}$ & .07 & $.16^{* *}$ & $.18^{* *}$ & $.13^{*}$ & .06 & .12 & -- & & & \\
\hline 12. Age & .08 & $.12 *$ & $.20 * *$ & .08 & .13 & -.01 & .05 & $.14^{* *}$ & .11 & $.17^{*}$ & .04 & -- & & \\
\hline 13. General-RS & $.59 * *$ & $.38^{* *}$ & $.34^{* *}$ & $.32 * *$ & .55 & $.36^{* *}$ & .26 & $.21^{* *}$ & .42 & .32 & .08 & .04 & -- & \\
\hline 14. Attractiveness & -.04 & -.04 & .09 & -.05 & .01 & -.07 & -.12 & -.04 & -.02 & $.20 * *$ & $-.19 * *$ & .08 & -.04 & -- \\
\hline$M$ & 10.55 & 9.92 & 1.81 & 5.73 & 2.11 & 3.94 & 1.73 & 2.02 & 1.88 & 2.70 & 49.53 & 12.00 & 8.40 & -0.04 \\
\hline$S E$ & 0.38 & 0.39 & 0.04 & 0.54 & 0.08 & 0.24 & 0.09 & 0.04 & 0.10 & 0.08 & 1.56 & 0.05 & 0.31 & 0.05 \\
\hline
\end{tabular}

Note. All variables are T1, except for Appearance-RS T2. App. = appearance. Intern. = internalization.

${ }^{*} p<.05 .{ }^{* *} p<.01$. 
Table 2

Results of a Path Model Testing Associations of T1 Appearance-RS with T1 Sociocultural Influence and Control Variables $(N=365)$

\begin{tabular}{lccccccc}
\hline & & \multicolumn{7}{c}{$95 \%$ CI $B$} & & \\
\cline { 5 - 6 } Independent Variables & $B$ & $S E(B)$ & Lower & Upper & $\beta$ & $p$ \\
\hline BMI percentile & 0.01 & 0.01 & -0.01 & 0.03 & .04 & .43 \\
General rejection sensitivity & 0.72 & 0.10 & 0.52 & 0.92 & $.41^{* *}$ & $<.01$ \\
Attractiveness & -0.46 & 0.23 & -0.91 & -0.01 & -.06 & .20 \\
Peer appearance conversations & 0.13 & 0.42 & -0.71 & 0.96 & .02 & .31 \\
Peer appearance teasing & 0.09 & 0.04 & 0.01 & 0.19 & $.12^{*}$ & .01 \\
Peer appearance pressure & 1.59 & 0.59 & 0.36 & 2.75 & $.21^{* *}$ & $<.01$ \\
Parent appearance teasing & 0.37 & 0.12 & 0.14 & 0.62 & $.18^{* *}$ & $<.01$ \\
Family appearance pressure & -0.04 & 0.44 & -0.88 & 0.90 & .01 & .44 \\
Parent appearance attitudes & -0.08 & 0.42 & -0.94 & 0.72 & & -.01 & .58 \\
Media pressure & 0.03 & 0.44 & -0.88 & 0.88 & .01 & .34 \\
Internalization media ideals & 1.77 & 0.37 & 0.99 & 2.48 & $.24^{* *}$ & $<.01$ \\
\hline
\end{tabular}

Note. $R^{2}=.59,95 \% C I=0.52-0.67 . C I=$ confidence interval. ${ }^{*} p<.05 . * * p<.01$. 
Table 3

Results of a Path Model Testing Associations of T2 Appearance-RS with T1 Sociocultural Influence, T1 Appearance-RS and Control Variables $(N=365)$

\begin{tabular}{|c|c|c|c|c|c|c|}
\hline \multirow[b]{2}{*}{ Independent variables } & \multirow[b]{2}{*}{$B$} & \multirow[b]{2}{*}{$S E(B)$} & \multicolumn{2}{|c|}{$95 \% C I B$} & \multirow[b]{2}{*}{$\beta$} & \multirow[b]{2}{*}{$p$} \\
\hline & & & Lower & Upper & & \\
\hline BMI percentile & 0.02 & 0.01 & -0.01 & 0.04 & .06 & .15 \\
\hline General rejection sensitivity & 0.10 & 0.10 & 0.00 & 0.20 & .05 & .31 \\
\hline Attractiveness & -0.13 & 0.34 & -0.47 & 0.21 & -.02 & .69 \\
\hline Appearance-RS T1 & 0.42 & 0.06 & 0.30 & 0.52 & $.41^{* *}$ & $<.001$ \\
\hline Peer appearance conversations & 0.73 & 0.42 & 0.31 & 1.15 & .08 & .08 \\
\hline Peer appearance teasing & -0.01 & 0.03 & -0.08 & 0.05 & -.02 & .70 \\
\hline Parent appearance teasing & 0.22 & 0.09 & 0.14 & 0.31 & $.12^{*}$ & .01 \\
\hline Parent appearance attitudes & 0.90 & 0.46 & 0.44 & 1.36 & $.09 *$ & .05 \\
\hline Media pressure & 0.68 & 0.38 & 0.01 & 1.36 & .09 & .07 \\
\hline Internalization media ideals & 0.35 & 0.39 & -0.04 & 0.73 & .05 & .89 \\
\hline
\end{tabular}

Note. $R^{2}=.45,95 \% C I=0.36-0.54$. $C I=$ confidence interval. ${ }^{*} p \leq .05 . * * p<.01$. 


\section{Table 4}

Means, Standard Deviations, and Correlations Between All Variables for Boys and Girls $(N=365)$

\begin{tabular}{|c|c|c|c|c|c|c|c|c|c|c|c|c|c|c|}
\hline Variable & 1 & 2 & 3 & 4 & 5 & 6 & 7 & 8 & 9 & 10 & 11 & 12 & 13 & 14 \\
\hline 1. App-RS T1 & - & $.61^{* *}$ & $.34^{* *}$ & $.40^{* *}$ & $.44^{* *}$ & $.27^{* *}$ & $.24^{* *}$ & $.27^{* *}$ & $.32^{* *}$ & $.36^{* *}$ & .15 & .10 & $.45^{* *}$ & -.07 \\
\hline 2. App-RS T2 & $.59^{* *}$ & -- & $.28^{* *}$ & $.32^{* *}$ & $.32^{*}$ & $.31^{* *}$ & .16 & $.21^{* *}$ & .19 & .17 & .13 & $.17^{*}$ & $.19^{*}$ & -.08 \\
\hline 3. Peer app conv & $.43^{* *}$ & $.32^{* *}$ & -- & .10 & $.53^{* *}$ & .14 & $.37^{* *}$ & $.27^{* *}$ & $.32^{* *}$ & $.38^{* *}$ & -.07 & $.16^{*}$ & .23 & $.19^{*}$ \\
\hline 4. Peer app teas & $.50^{* *}$ & $.34^{* *}$ & $.25^{* *}$ & -- & $.29^{* *}$ & $.27^{* *}$ & .18 & $.28^{* *}$ & $.19^{*}$ & .15 & $.19^{*}$ & .09 & $.20^{*}$ & -.04 \\
\hline 5. Peer app pres & $.67^{* *}$ & $.43^{* *}$ & $.55^{* *}$ & $.47^{* *}$ & -- & .12 & $.36^{* *}$ & $.22^{*}$ & $.51^{* *}$ & $.30^{* *}$ & -.08 & .13 & .39 & .07 \\
\hline 6. Parent app teas & $.49^{* *}$ & $.41^{* *}$ & $.28^{* *}$ & $.49^{* *}$ & .43 & -- & .23 & .16 & .08 & .04 & .09 & -.06 & .15 & -.06 \\
\hline 7. Fam app pres & $.40^{* *}$ & $.22^{*}$ & $.25^{* *}$ & $.36^{* *}$ & $.47^{* *}$ & .33 & -- & $.31^{* *}$ & $.31^{* *}$ & .12 & $.19^{*}$ & .02 & .16 & -.07 \\
\hline 8. Parent app att & $.23^{* *}$ & $.31^{* *}$ & $.21^{* *}$ & $.16^{*}$ & $.27^{* *}$ & $.26^{* *}$ & $.25^{* *}$ & -- & .20 & $.25^{* *}$ & .12 & $.16^{*}$ & .13 & -.04 \\
\hline 9. Media pres & $.56^{* *}$ & $.35^{* *}$ & $.46^{* *}$ & $.43^{* *}$ & $.71^{* *}$ & .42 & $.50^{* *}$ & $.26^{* *}$ & -- & $.44^{* *}$ & -.03 & .15 & .23 & .03 \\
\hline 10. Inter media & $.54^{* *}$ & $.35^{* *}$ & $.47^{* *}$ & $.37^{* *}$ & $.55^{* *}$ & .32 & $.25^{*}$ & $.25^{* *}$ & $.54^{* *}$ & -- & .05 & .13 & .15 & $.22^{*}$ \\
\hline 11. BMI \% & $.18^{*}$ & $.23^{* *}$ & $.21^{* *}$ & $.15^{*}$ & .16 & $.22^{* *}$ & .18 & .13 & .11 & .17 & -- & .01 & -.01 & $-.19^{*}$ \\
\hline 12. Age & .08 & .12 & $.25^{* *}$ & .08 & .14 & .02 & .07 & .13 & .10 & $.21^{*}$ & .08 & -- & .05 & .08 \\
\hline 13. General-RS & $.64^{* *}$ & $.43^{* *}$ & $.37^{* *}$ & $.36^{* *}$ & .61 & $.46^{* *}$ & .32 & $.24^{* *}$ & $.45^{*}$ & $.40^{*}$ & .15 & .04 & -- & -.07 \\
\hline 14. Attractiveness & -.08 & -.10 & .01 & -.08 & -.05 & -.10 & -.15 & -.05 & -.08 & .15 & $-.21^{* *}$ & .09 & -.06 & -- \\
\hline Boys, $M$ & 8.57 & 7.25 & 1.55 & 4.37 & 1.92 & 3.48 & 1.71 & 1.96 & 1.70 & 2.46 & 48.70 & 12.02 & 7.89 & -0.17 \\
\hline Boys, SE & 0.39 & 0.39 & 0.05 & 0.59 & 0.09 & 0.32 & 0.12 & 0.05 & 0.13 & 0.09 & 2.45 & 0.07 & 0.35 & 0.06 \\
\hline Girls, $M$ & 12.24 & 12.18 & 2.02 & 6.89 & 2.27 & 4.32 & 1.74 & 2.06 & 2.04 & 2.90 & 50.22 & 11.99 & 8.83 & 0.07 \\
\hline $\begin{array}{l}\text { Girls, SE } \\
\text { Gender comp }\end{array}$ & 0.59 & 0.59 & 0.07 & 0.86 & 0.10 & 0.35 & 0.10 & 0.05 & 0.11 & 0.09 & 2.01 & 0.06 & 0.41 & 0.08 \\
\hline$t(363)$ & $-4.95 * *$ & $-6.73^{* *}$ & $-5.51 * *$ & $-2.32 *$ & $-3.06 * *$ & -1.77 & -0.25 & -1.43 & $-2.85 * *$ & $-4.18 * *$ & -0.48 & 0.30 & -1.96 & $-2.44^{*}$ \\
\hline
\end{tabular}

Note. All variables are T1, except for T2 Appearance-RS. Correlations above the diagonal are for boys. Correlations below the diagonal are for girls.

App. $=$ appearance. Inter. $=$ internalization. Conv $=$ conversations. Pres $=$ pressure. Fam $=$ family. Att $=$ attitudes. Teas $=$ teasing. Comp $=$ comparison. ${ }^{*} p<.05 .{ }^{* *} p<.01$. 


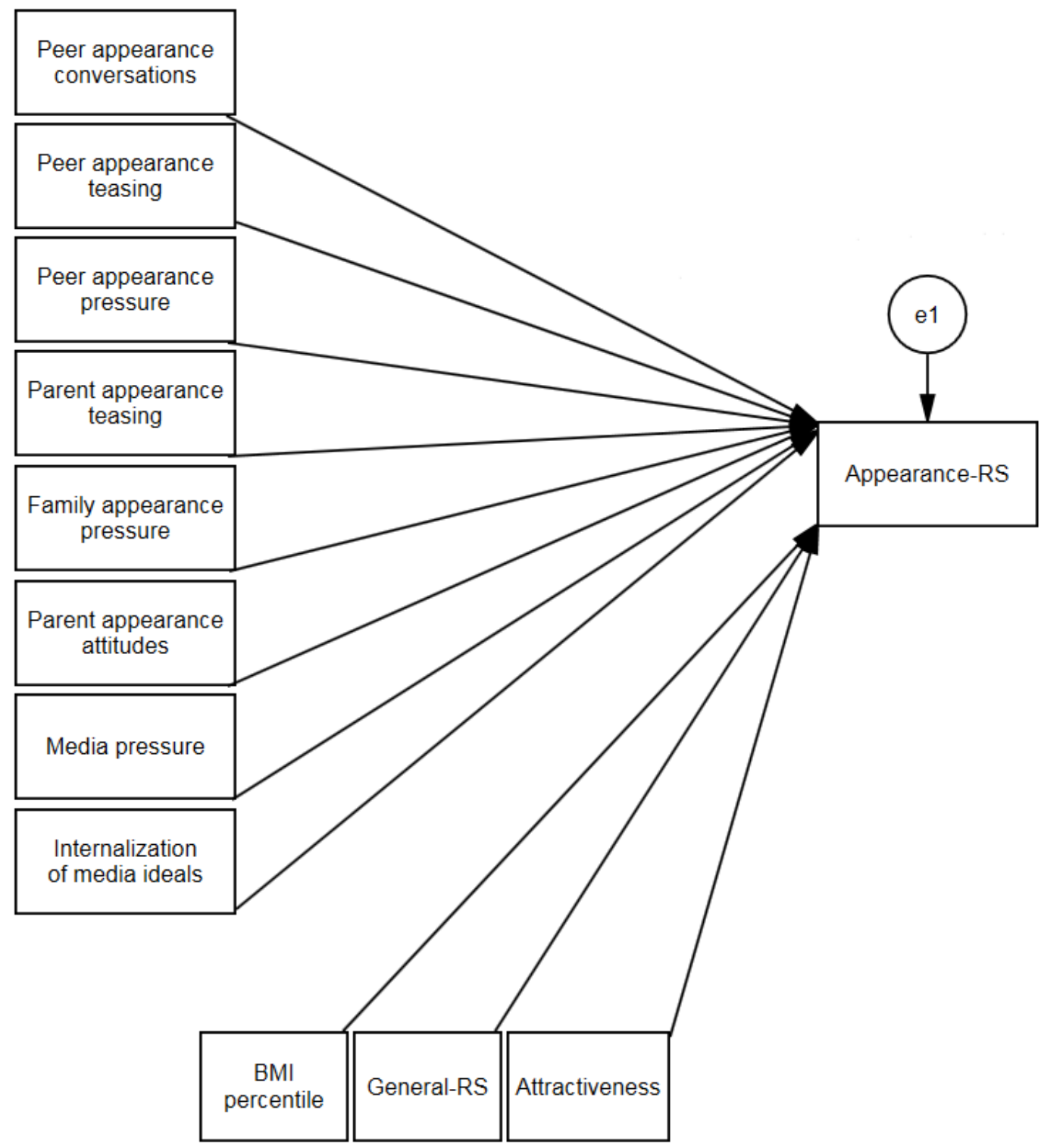

Figure 1. An illustration of all measures and the hypothesized prospective model of appearanceRS.

Note. Prospective model predicting T2 appearance-RS also includes T1 appearance-RS as a covariate. It is not shown here to slightly simplify the model. 